\title{
MJN CROSS-SECTIONAL STUDY ON ADVERSE PREGNANCY OUTCOMES AMONG FEMALE HEALTHCARE WORKERS IN KUCHING, SARAWAK
}

\author{
Gregory Xavier ${ }^{1 *}$, Anselm Su Ting ${ }^{1}$, Teh Jo Hun² \\ ${ }^{1}$ Department of Community Medicine and Public Health, Faculty of Medicine and Health Sciences, \\ Universiti Malaysia Sarawak, Sarawak, Malaysia \\ ${ }^{2}$ Divisional Health Office of Sibu, Wisma Persekutuan Persiaran Brooke, Sibu, Sarawak, Malaysia \\ *Corresponding Author 's Email: gregshc@yahoo.co.uk
}

\begin{abstract}
The weight of occupational risk on women in addition to men, is on their fecundity. NIOSH lists disorders of reproduction as one of the top ten leading work-related diseases and injuries. Nevertheless, women in the workforce is increasing and in healthcare, females make up the majority. This research is to observe the occurrences of adverse pregnancy outcomes among female healthcare workers in relation to their work schedules and its significance in relation to non-healthcare workers. A cross-sectional study was carried out using a questionnaire with 469 respondents; 339 healthcare and 130 non-healthcare workers, reporting 564 pregnancies. In this study, adverse pregnancy outcomes among female healthcare workers is significantly higher than non-healthcare workers. There are no significant findings between healthcare and non-healthcare workers with respect to the types of adverse pregnancy outcomes and the work schedule. However, from the respondents' lifetime pregnancy outcome, we find that complete miscarriage occurred more frequently among healthcare workers who work on shift. Healthcare workers do experience a higher risk of adverse pregnancy outcomes, commonly occurring among those who work on shift/on-call.
\end{abstract}

Keywords: Cross-Sectional Study, Adverse Pregnancy Outcomes, Female Healthcare Workers

\section{INTRODUCTION}

Pregnancy is a natural phenomenon and a process that ensures the continuation of the human species. Due to this natural ability, females need more health considerations and care. Tailored and specific programs are available to ensure their good health. In this period of advance development and progress, more and more women are becoming independent and carrying out roles, duties and jobs formerly dominated by men. With this, we see an increasing number of women into the workforce. Now, they too are exposed to hazards from the working environment similar to men (Burdorf et al., 2006). The health risk of these hazards on women is more over man. Their fecundity; their ability to reproduce and remain fertile is at higher risk compared to men. Many studies have showed that stressors from the working environment did affect reproductive system and over time. Hence, many precautionary measures had been developed to protect them.

Healthcare working environment is not free of hazards, which carry risk that can take effect on the reproductive system of female healthcare workers. The nature of healthcare work by itself, carries a large responsibility. Simply because it deals with human lives hence, we must try ensuring that there is close to no margin of error. Hence, there is no doubt in sentiment that psychosocial stress does exist here (Familoni, 2008). In addition to psychosocial stress, the long working hours with various time schedules also constitutes their working environment, which is also a risk-carrying hazard. The nursing section makes up the bulk of healthcare workers predominated by females. Hence, it is only rightful to explore their health risk. In this study, their pregnancy outcome reflects their fecundity.

The National Institute for Occupational Safety and Health (NIOSH) lists disorders of reproduction as one of the top ten leading work-related diseases and injuries (Burdorf et al., 2006; Figà-Talamanca, 2006; Yamada, 1986). However currently there is no surveillance for such disorders of reproduction at national level. Moreover, hazards due to occupation or otherwise is not listed in Malaysia. Following NIOSH and reviews from 
literature, complete miscarriage, threatened miscarriage, prematurity, low birth weight, hypertensive disorders in pregnancy and others categories of adverse pregnancy outcomes (NIOSH 2017) is studied in this paper.

The common stressor attributed to the stressful healthcare working environment is the work schedule and hours. Long and changing work schedules has been reported to contribute to the increase in adverse pregnancy outcomes especially among healthcare staff (Harrington 2001; Hakola, Härmä \& Laitinen 1996; Gabbe et al., 2003). In Sarawak, the work schedule depends on the occupation and duties. The nurses commonly practice the rotating shift system similarly practiced in the United Kingdom (Royal College of Physicians, 2013). A normal rotation of a day shift followed by an evening shift and then a night shift makes up an average of 45 working hours per week. The on-call work schedule normally carried out by doctors and some allied health staff workers up to 32 hours in a row and may continue with another round the following day making up more than 70 hours per week of work. The last work schedule is the usual office hours where the staff only works 8 hours per day for 5 days.

This paper studies the occurrences of adverse pregnancy outcomes among female healthcare workers in relation to their work schedules and its significance in relation to non-healthcare workers.

\section{METHODOLOGY}

The healthcare workers were from the only tertiary healthcare centre in Sarawak, Malaysia, which best represents the working environment for healthcare workers. To represent a contrasting working environment, we recruited non-healthcare workers from a government tertiary education centre. The number of eligible non-healthcare workers in the tertiary healthcare centre were too few to produce a statistical analysis. We universally sampled the respondents based on a vetted name list according to a set criterion. Calculating the sample size was based on proportionate sampling on the female population in both the studied institutions. The proportion took account the Sarawak state birth rate.

We used a questionnaire to conduct this crosssectional study. The questionnaire elicits the respondents' demography, pregnancy history and its concurrent work history. We included females who have had an experience of pregnancy in the past three years and the history for each pregnancy was elicited (lifetime analysis deduced). Due to the effect of age increasing risk of adverse pregnancy outcome, those who has experienced pregnancy up to the age of 35 were included. Hence, the maximum age of a respondent included is 38 years (Kenny et al., 2013).

Statistical analysis includes descriptive statistics involving identification of total number of healthcare and non-healthcare subjects who had any adverse pregnancy outcome and related to work schedule for healthcare workers. Bivariate analysis was used to describe the respondents' sociodemographic factors with the adverse pregnancy outcomes. For the healthcare workers the analysis was carried out with the work schedule, instead.

\section{RESULTS}

Table 1 presents the events of adverse pregnancy experienced in the last three years. The most frequently occurring adverse event is deduced as lifetime adverse pregnancy outcome. Out of the 469 respondents who experienced a pregnancy in the last three years, 120 of them had experienced an adverse outcome at least once. 98 of them were among healthcare workers $(81.7 \%)$. This difference is significant $\left[\chi^{2}(\mathrm{df})=0.008(1)\right.$, $p<0.01]$.

The average age (standard deviation) of the respondents is 31.9 (3.4) years, minimum age is 23 years. The average age (SD) during pregnancy among all the respondents is 30.2 (3.3) years. There is a statistically significant difference $(p<0.05)$ in the mean age between healthcare and non-healthcare workers. Hundred and seven respondents had experienced an adverse pregnancy outcome in their latest pregnancy. Among them, those between the age of 30 to 38 years, there were 88 of them and it was significant at $[\chi 2$ $(d f)=0.027(1), p<0.05]$. However, only 85 of them were healthcare workers and the difference were not significant. Nevertheless, the significance of job description is seen in those who experienced adverse pregnancy outcome in their $1^{\text {st }}$ prior pregnancy $[\chi 2$ $(d f)=0.003(1), p<0.01]$ and not among those between ages 30 to 38 .

Adverse pregnancy outcomes occurring among healthcare workers is significant in this study. It is seen that majority of the respondents are nurses. About 78 out of 260 of them had experienced a lifetime adverse pregnancy outcome significant at $\left[\chi^{2}(d f)=0.044(3)\right.$, $p<0.05]$ and 22 out of 59 of them during their 1st prior pregnancy $\left[\chi^{2}(d f)=0.00(3), p=0.01\right]$. Very few respondents had experienced three pregnancies in a row hence, the number of adverse pregnancies at their second prior pregnancy were too few for analysis.

Race, income and education factors were not significant. No respondent claimed consuming drugs, alcohol and smoking. None also reported any comorbidities. 
The analysis of the effect of work schedule on pregnancy outcomes were carried out only among the healthcare staff. The results were not significant in any of the pregnancies. Nevertheless, those who work oncall and shift did experienced more frequent adverse pregnancy outcomes.

Table 1: Percentage distribution of adverse pregnancy outcome among respondents following their socio demographic characteristics.

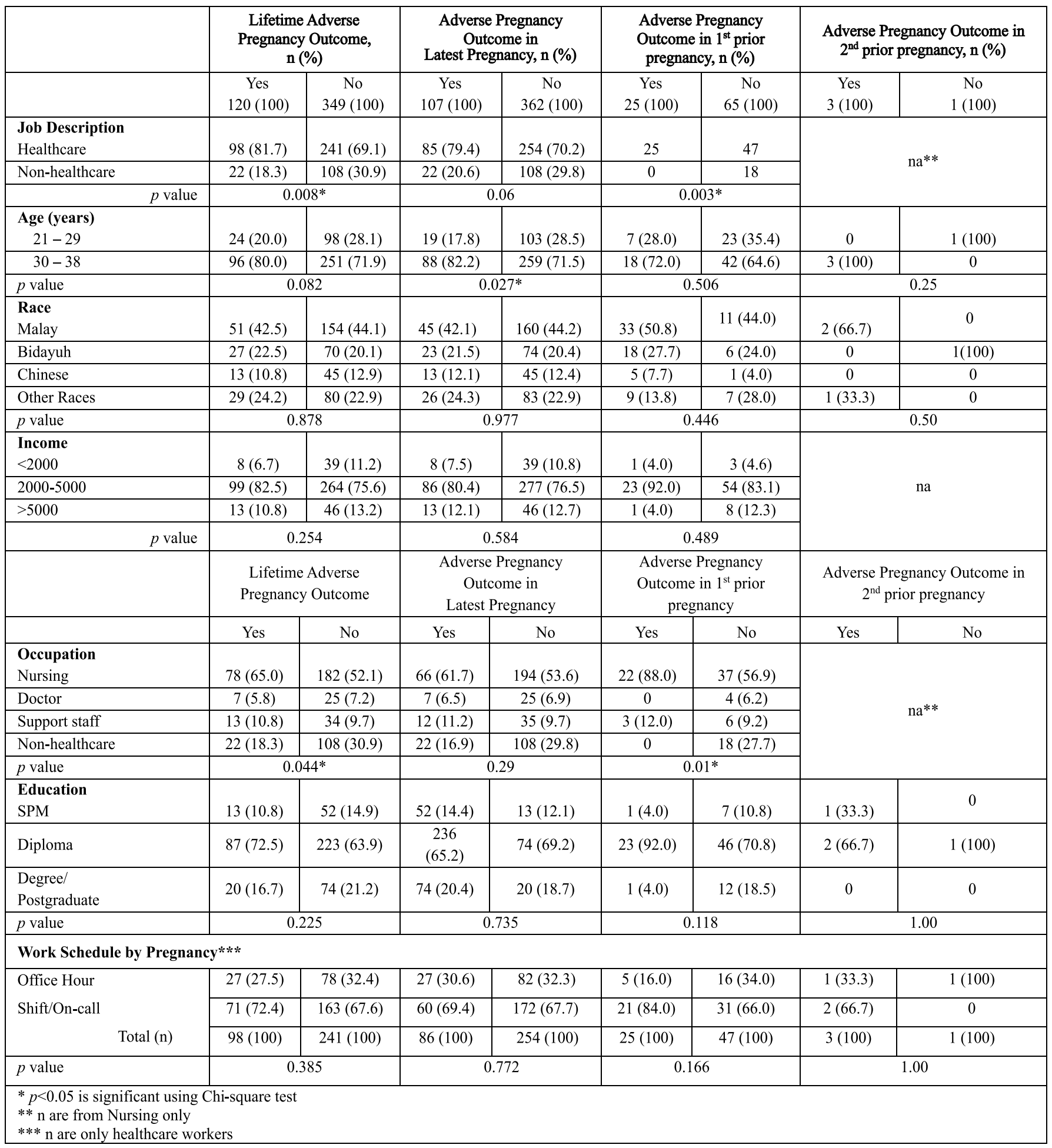


In Table 2, healthcare workers adverse pregnancy outcomes occur most frequently among those who work in shifts. Following this, complete miscarriage is frequent followed by hypertensive disorders in pregnancy, low birth weight and others. There is however no significant relationship between adverse pregnancy outcomes and work schedule in this study among the healthcare workers.

Table 2: Percentage Distribution of Lifetime Adverse Pregnancy Outcome of Healthcare Workers Over Their Lifetime Work Schedule.

\begin{tabular}{|l|r|l|r|r|r|r|}
\hline & \multicolumn{6}{|c|}{ Lifetime work schedule, n (\%) } \\
\hline $\begin{array}{l}\text { Lifetime Adverse } \\
\text { Pregnancy Outcome }\end{array}$ & \multicolumn{2}{|c|}{$\begin{array}{l}\text { Office } \\
\text { hours }\end{array}$} & \multicolumn{2}{|c|}{ shift } & \multicolumn{3}{|c|}{ On-call } \\
\hline Complete miscarriage & 7 & $(25.9)$ & 18 & $(29.0)$ & 2 & $(22.2)$ \\
\hline Low birth weight & 6 & $(22.2)$ & 11 & $(17.7)$ & 5 & $(55.6)$ \\
\hline Other complications & 9 & $(33.3)$ & 13 & $(21.0)$ & 0 & $(0)$ \\
\hline Prematurity & 2 & $(7.4)$ & 4 & $(6.5)$ & 1 & $(11.1)$ \\
\hline $\begin{array}{l}\text { Hypertensive Disorders } \\
\text { in Pregnancy }\end{array}$ & 2 & $(7.4)$ & 14 & $(22.6)$ & 0 & $(0)$ \\
\hline Threatened Miscarriage & 1 & $(3.7)$ & 2 & $(3.2)$ & 1 & $(11.1)$ \\
\hline \multicolumn{1}{|c|}{ Total } & \multicolumn{2}{|c|}{$27(100)$} & $(100) 62$ & \multicolumn{2}{|c|}{$9(100)$} \\
\hline
\end{tabular}

\section{DISCUSSION}

Extreme of ages in pregnancy; less than 20 years and more than 35 years of age, are associated with higher risk of adverse pregnancy outcomes. In addition, increasing age beyond 'prime age' to be pregnant do carry increasing risk although not as significant as the extreme ages (Cleary-Goldman et al., 2005; Kenny et al., 2013). However, this study has findings with a significant result at the adverse pregnancy outcome in case of latest pregnancy as seen in table $1(p=0.0027)$. The mean age during pregnancy is 30.2 years. Hence, this significant finding shows the presence of external risk in causing adverse pregnancy outcomes.

There are reports $23 \%$ of working women suffering adverse pregnancy outcomes compared to $19.1 \%$ among non-working women. For healthcare workers, $76.3 \%$ of them had suffered at least one adverse pregnancy outcome, compared to $55.9 \%$ of females from non-healthcare related work (Park et al., 2017). An observational study review (Mozurkewich et al. 2000) and also a study on nurses (Kim et al., 2017) conclude that working hours pose an effect on causing adverse pregnancy outcomes. This study supports that healthcare workers have significantly more chances of experiencing adverse pregnancy outcomes. But it fails to prove that work schedule is a possible cause of adverse outcomes, despite the count of adverse being higher among those carrying out on-call and shift work. Royal College of Physicians, 2013 stated that this debate is inconclusive but with the balance of evidence, the possible effect is highly suggestive.

Since disorders of reproduction is one of the leading work-related diseases and injuries (Yamada, 1986) it warrants a surveillance system. Other studies (Niedhammer et al., 2009) too have recommended such measures and in Sarawak, it may be done by optimizing the Birth Information Database System and including work history into the antennal book. A study also recommends that if ever possible to not allow pregnant women to work extended hours or shift (Harrington, 2001).

\section{LIMITATIONS}

In comparison to other studies, this study warrants a large sample size, however due to the limitations of a small population be it in Sarawak or in the institutions concerned a matching sample size is unobtainable. Nevertheless, the findings still did show similarities to the common findings from literature though not statistically significant. To achieve a similar sample size would need to process data from the whole country however; there is no record or system in place surveying adverse pregnancy outcomes by occupation or work schedule.

The non-healthcare workers were all from a single different institution and were all under office hour work schedule. This limits the correlation according to work schedule with the healthcare workers. Hence, the different environmental factor arising from the choice of a different institution could only be matched under the office hour work schedule. The number of nonhealthcare workers in the tertiary hospital who fits the inclusion criteria is too small for analysis.

It was a challenge in ensuring the integrity of the data obtained. Bias was limited to reporting pregnancies in the last three years. The data obtained was crossexamined with local online birth record system but itself is not comprehensive enough.

\section{RECOMMENDATIONS}

The small sample size in this research inhibited the reflection of significant relationships. A wider sampling frame and sample size be obtained if ever this research is to be duplicated.

This study found that other adverse pregnancy outcomes were high in occurrence. This other adverse 
pregnancy outcomes mainly include gestational diabetes mellitus and anaemia in pregnancy. There may be a need to investigate further the nutritional intake among pregnant healthcare workers.

\section{CONCLUSION}

This study has only partly concurred with literature's general sentiment whereby healthcare workers do carry a higher risk in developing adverse pregnancy outcome (statistically significant in this study). Those working shift are even more susceptible and complete miscarriage is the most common adverse outcome (despite not being statistically significant). This study however could not proof the statistical significance between the work schedule and adverse pregnancy outcome due to its limitations.

\section{REFERENCES}

Burdorf, A., Figà-Talamanca, I., Jensen, T.K. \& Thulstrup, A.M. (2006). Effects of Occupational Exposure on the Reproductive System: Core Evidence and Practical Implications. Occupational Medicine, 56(8), pp 516-520.

Cleary-Goldman, J., Malone, F.D., Vidaver, J., Ball, R.H., Nyberg, D.A., Comstock, C.H., Saade, G.R., Eddleman, K.A., Klugman, S., Dugoff, L., Timor-Tritsch, I.E., Craigo, S.D., Carr, S.R., Wolfe, H.M., Bianchi, D.W., D'Alton, M.; FASTER Consortium (2005). Impact of maternal age on obstetric outcome. Obstetrics and Gynecology, 105(5 Pt 1): 983-990.

Familoni, O.B. (2008). An Overview of Stress in Medical Practice. African Health Sciences, 8(1), pp 6-7.

Figà-Talamanca, I. (2006). Occupational Risk Factors and Reproductive Health of Women. Occupational Medicine (Oxford, England), 56(8), pp 521-531.

Gabbe, S.G., Morgan, M.A., Power, M.L., Schulkin, J. \& Williams, S.B. (2003). Duty hours and pregnancy outcome among residents in obstetrics and gynecology. Obstetrics \& Gynecology, 102(5 Pt 1), pp 948-951.

Hakola, T., Härmä, M.I. \& Laitinen, J.T. (1996). Circadian adjustment of men and women to night work. Scandinavian Journal of Work, Environment \& Health, 22(2), pp 133-138.

Harrington, J.M. (2001). Health Effects of Shift Work and Extended Hours of Work. Occupational and Environmental Medicine, 58(1), pp 68-72.

Kenny, L.C., Lavender, T., McNamee, R., O'Neill, S.M., Mills, T. \& Khashan, A.S. (2013). Advanced maternal age and adverse pregnancy outcome: evidence from a large contemporary cohort. PloS one, 8(2), e56583.

Kim, O., Ahn, Y., Lee, H.Y., Jang, H.J., Kim, S., Lee, J.E., Jung, H., Cho, E., Lim, J.Y., Kim, M.J., Willett, W.C., Chavarro, J.E. \& Park, H.Y. (2017). The Korea Nurses' Health Study: A Prospective Cohort Study. Journal of Women's Health, 26(8), pp 892-899.

Mozurkewich, E.L., Luke, B., Avni, M. \& Wolf, F.M. (2000). Working Conditions and Adverse Pregnancy Outcome: A Meta-Analysis. Obstetrics and Gynecology, 95(4), pp 623-635.

Niedhammer, I., O'Mahony, D., Daly, S., Morrison, J.J., Kelleher, C.C.; Lifeways Cross-Generation Cohort Study Steering Group. (2009). Occupational Predictors of Pregnancy Outcomes in Irish Working Women in the Lifeways Cohort. BJOG: An International Journal of Obstetrics and Gynaecology, 116(7), pp 943-952.

National Institute for Occupational Safety and Health. CDC 24/7: Saving Lives, Protecting People. U.S. Department of Health \& Human Services. Centre for Disease Control and Prevention.

Park, C., Kang, M.Y., Kim, D., Park, J., Eom, H. \& Kim, E.A. (2017). Prevalence of Abortion and Adverse Pregnancy Outcomes among Working Women in Korea: A Cross-Sectional Study. PloS one, 12(8), e0182341.

Royal College of Physicians. (2013). Advising women with a healthy, uncomplicated,

singleton pregnancy on: heavy lifting and the risk of miscarriage, preterm delivery and small for gestational age. Faculty of Occupational Medicine, United Kingdom. Retrieved from: http://www.nhshealthatwork. co.uk/images/library/files/Clinical\%20excellence/Pregnancy_info_shiftwork_A4.pdf.

Yamada, S. (1986). The ten leading work-related diseases and injuries proposed by the National Institute for Occupational Safety and Health (NIOSH). Journal of UOEH, 8(4): pp 457-469. 